\title{
Global poverty and inequality from 1980 to the COVID-19 pandemic
}

Authors:

Mark W. Moses, MHS

Homi Kharas, PhD

Molly K. Miller-Petrie, MSc

Goli Tsakalos, MS

Laurie Marczak, PhD

Simon I. Hay, DSc

Christopher J.L. Murray, DPhil

Joseph L. Dieleman, PhD

Correspondence: Joseph L Dieleman

dieleman@uw.edu

Institute for Health Metrics and Evaluation

Words: $\quad 2,568$

Version: $\quad$ March 18, 2021 
2 The world made remarkable progress in reducing extreme poverty over the last twenty years. Recent

3 progress has slowed, ${ }^{1}$ however, and the economic damage wrought by the COVID-19 pandemic ${ }^{1-3}$

4 imperils progress towards achieving the Sustainable Development Goals (SDGs) of eradicating extreme

5 poverty and alleviating inequality by the year 2030. To track progress towards the SDGs, we collated-to

6 the best of our knowledge - the largest collection of poverty and inequality related data and developed

7 novel methods to construct comprehensive and comparable estimates of poverty and inequality from

81980 to 2019 in 204 countries and territories, across urban and rural settings, and by age; further, we

9 forecast the effects of the COVID-19 pandemic on poverty out to 2021 . We find that over the past four

10 decades, the number of individuals living in extreme poverty declined dramatically, however, extreme

11 poverty counts were rising in Sub-Saharan Africa. The Millennium Development Goal (MDG) era

12 corresponded to the fastest observed reduction in extreme poverty and a period of more equitable

13 growth. Progress made is jeopardized by the economic shock resulting from the COVID-19 pandemic.

14 Estimates of poverty through 2021 highlight the effect of the global economic shock, the effect of

15 governments' economic responses to the pandemic, and the need to build economies resilient to the 16 next global threat. 


\section{Main}

18 The 2015 United Nations' Sustainable Development Goals (SDGs) aspired to set a global course for peace

19 and prosperity of all people and the planet by $2030^{4}$. The aims of the SDGs are enshrined in a set of 17

20 global goals that call for all signatory countries to realize their common responsibility in achieving a

21 safer, more just, and sustainable world ${ }^{5}$. Progress on any one of the 17 SDGs does not occur in isolation

22 as evidence suggests the SDGs are interconnected and progress on one goal may have spillover effects

23 on progress on other goals ${ }^{6}$. Two goals that have the greatest positive spillover effects are the

24 eradication of extreme poverty and alleviation of inequality ${ }^{7-10}$.

25 In 2000, the precursors to the SDGs, the Millennium Development Goals (MDGs) set a target to

26 cut in half the proportion of the world's population living in extreme poverty by 2015; the goal was

27 achieved five years ahead of schedule ${ }^{11}$. Momentum from this achievement may not have been

28 sustained ${ }^{1}$, and the economic damage due to COVID-19 interventions may place the SDG goal of

29 eradicating extreme poverty further out of reach ${ }^{1}$.

Despite their global significance, efforts to measure progress on poverty eradication and

31 alleviation of inequality remain imperfect. Existing global estimates of poverty and inequality are often

32 made with limited data and rely on regional averages for imputation ${ }^{1}$, and in many cases the underlying

33 data used in estimation lacks comparability, limiting cross country comparisons ${ }^{12,13}$. To address these

34 concerns, we amassed the largest collection of poverty and inequality related data, developed a novel

35 procedure to standardize the data, and implemented a nonparametric estimation process to measure

extreme poverty and inequality in 204 countries and territories between 1980 and 2019 in both urban

37 and rural settings by age. Further, we assess the profound economic effects of the COVID-19 pandemic

38 on poverty and the effect of government responses to the pandemic. 
Tracking absolute and relative poverty from 1980 to 2019

40 The SDGs define extreme poverty as the number of individuals living in households spending less than

$41 \$ 1.90$ a day per person in 2011 purchasing power parity-adjusted (PPP) dollars ${ }^{14}-$ a unit of

42 measurement which adjusts for variations in the price of goods and services across countries and time.

43 We estimated the total number of individuals living in extreme poverty decreased by over 1.3 billion

44 from 1980 to 2019 (Fig 1C). The global decline in extreme poverty was driven especially by progress over

45 the past forty years in China and India, where the number of individuals living in extreme poverty was

46 reduced by approximately 850 and 350 million, respectively. The pace of this global decline slowed since

472009 , however, due primarily to growing extreme poverty in Sub-Saharan Africa.

The extreme poverty rate-or the percentage of the population living in extreme poverty-

49 declined from almost 45\% in 1980 to 8.3\% (UI 7.6-8.9\%) in 2019 (Fig 1B). Globally, urban poverty rates

50 were lower than rural poverty rates in all years of this study, but the gap between the two shrunk

51 dramatically, especially between 1990 and 2010 when the global rural poverty rate fell sharply.

52 Approximately $25 \%$ of individuals living in extreme poverty lived in urban settings in 2019-an increase

53 from $15 \%$ in 1980.

The eradication of extreme poverty is defined as an extreme poverty rate of less than $3 \%{ }^{15}$. In

552019,121 out of 204 countries eradicated extreme poverty-an increase of 46 countries since 1980.

56 Extreme poverty was concentrated in Sub-Saharan Africa: 32 of the 35 countries with extreme poverty

57 rates above 25\% were within Sub-Saharan Africa in 2019 (Fig. 1C). Burundi, Central African Republic, The

58 Democratic Republic of the Congo, and Somalia were the only countries with extreme poverty rates

59 exceeding 60\% in 2019 (Fig 1C). Nigeria and India were the only countries with over 75 million

60 individuals living in extreme poverty in 2019.

61

The extreme poverty line of $\$ 1.90$ a day becomes less relevant as countries grow economically

62 and the vast majority of populations move out of extreme poverty. Instead, the relative poverty rate

63 becomes an increasingly valuable measure as it quantifies both country-specific poverty and serves as a 
measure of inequality. The relative poverty rate is defined as the proportion of individuals living on less

65 than $50 \%$ of the median standard of living (the value of all goods and services consumed) ${ }^{14}$. Because the median standard of living varies across countries and changes over time, the relative poverty line is

67 country and year specific measure. The SDGs use relative poverty to measure progress towards

68 alleviation of inequality (SDG 10.2.1). Between 1980 and 2019, the number of countries with a relative

69 poverty rate exceeding $20 \%$ declined from 31 to seven. Six of the seven countries were in sub-Saharan

$70 \quad$ Africa (Fig 1D).

71 Demography and poverty

72 The number of individuals living in extreme poverty fell over the past forty years despite the global

73 population growing by over three billion ${ }^{16}$. As the population grew, two other important demographic

74 changes occurred: (1) the world became more urban as the fraction of the world's population living in

75 urban areas expanded from $40 \%$ to $55 \%{ }^{17}$, and (2) the world's population aged, with the median age of

76 the population growing by over ten years ${ }^{17}$. In 1980 , the shape of both the urban and rural population

77 distributions followed a pyramid shape (Fig 2). By 2019, the population distribution in urban settings

78 grew more stationary while the rural population distribution maintained a pyramid shape (Fig 2). The

79 change in urban population distribution was driven by individuals making more than $\$ 11$ a day-a result

80 largely due to China's changing demographics (Extended Data Fig 1) and rising economic prosperity

81 (Extended Data Fig 2). In 2019, nearly 4.3 billion individuals (55\% of the world's population) lived on

82 more than $\$ 11$ a day-an increase of almost three billion since 1980 ; of these individuals, $70 \%$ lived in

83 urban settings, 45\% were between the ages of 15 and $45,37 \%$ lived in China or India, and 50\% lived in

84 Asia more broadly.

From 1980 to 2019, the number of children under the age of 15 living in extreme poverty fell

86 from approximately 890 million to 225 million, but still accounted for $40 \%$ of the population living in

87 extreme poverty in 2019 (Fig 2). We estimate it would cost over USD2021 51 billion annually to lift every 
child under the age of 15 out of extreme poverty and USD2021 98 billion to lift every individual out of

89 extreme poverty in 2019.

90 The pace and pattern of growth

91 Over the last four decades, the world grew more equal as the standard of living of the poorest grew

92 faster than that of the wealthiest-though the pattern of growth in the standard of living was not

93 constant over time (Fig 3A). From 1980 to 2000, the growth in the standard of living followed the

94 classical $S$ shape pattern - popularly likened to the silhouette of an elephant ${ }^{18-20}$-where the growth in

95 the standard of living of the poorest $50 \%$ and wealthiest $10 \%$ outpaced those in the middle $\left(50-90^{\text {th }}\right.$

96 percentiles). By removing the contributions of China and India to the global pattern, the standard of

97 living of the poorest three quarters of the world declined from 1980 to 2000, while the standard of living

98 of the wealthiest grew (Extended Data Fig 3). Conversely, during the MDGs (2000-2015) and the SDGs

99 (2016-2019), growth in standard of living of the poorest 50\% far outpaced the growth in the standard of

100 living of the wealthiest (with or without the contributions of China and India, Extended Data Fig 3), a

101 critical condition for dramatically reducing global inequality. Despite this relative success, the absolute

102 standard of living of the poorest three quarters of the global population grew by less than $\$ 1,000$ a year;

103 in contrast, the standard of living of the wealthiest grew by over $\$ 7,000$ a year (Extended Data Fig 3).

104 Countries also grew more equitably, on average, over the last 40 years (Fig 3B). From 1980 to

1052000 , within country inequality grew as the standard of living of the wealthiest increased slightly faster

106 than the poor; but during the MDGs, the pattern reversed, as countries grew more equally (Fig 3B). This

107 pattern of growth persisted during the first four years of the SDGs, however, the magnitude of

108 annualized growth in the standard of living across all percentiles during the MDGs was almost twice as

109 large as growth during the SDGs (Fig 3B). These conclusions remain robust even after adjusting for

110 unaccounted consumption that arises due to difficulty in surveying the very wealthiest (see

111 Supplemental Materials). 
112

113 To build more equitable, resilient, and cohesive societies that protect the most vulnerable, SDG 10.1.1

114 calls for countries to both grow economically and reduce inequality by promoting inclusive growth ${ }^{14}$.

115 Inclusive growth is achieved when there is both growth in the mean standard of living and a positive

116 shared prosperity premium, which is the difference between the growth rate of the mean standard of

117 living of the poorest $40 \%$ and the growth rate of the mean standard of living ${ }^{1}$. A positive shared

118 prosperity premium can either indicate that growth in the poor's standard of living advances faster

119 while the mean standard of living is growing, or during times of declining mean standard of living, that

120 changes in the poor's standard of living remain protected. times the number of countries that grew inclusively from 1980 to 2000 (44 countries; Extended Data Fig

4). We estimate countries' failure to grow inclusively from 1980 to 2000 prevented approximately 210 million individuals from escaping extreme poverty. In comparison, inclusive growth during the MDGs lifted over 150 million individuals from extreme poverty. Despite the success of the MDGs, the number of countries that grew inclusively during the first four years of the SDGs declined slightly to 124 and the magnitude of the shared prosperity premium also receded (Extended Data Fig 4).

\section{Estimating the effect of COVID-19 on poverty}

The world and its economic systems were shocked by the COVID-19 pandemic in $2020^{3,21}$. The exact human and economic toll of the COVID-19 pandemic is unknown and ongoing. We estimate the economic fallout in the wake of the COVID-19 pandemic pushed approximately 47 million into extreme poverty and 103 million into relative poverty in 2020, compared to a scenario where economic trends preceding COVID-19 persisted (Fig 4). Governments responded quickly by providing \$12 trillion in economic assistance during the first eight months of the pandemic, ${ }^{21}$ and we estimate these funds prevented approximately 24 million from entering into extreme poverty and 91 million from entering into relative poverty in 2020. Our estimates suggest the failure to extend government assistance into 
137 2021 - at a proportional level to the assistance disbursed in 2020-would result in nearly 23 million

138 individuals falling into extreme poverty and 72 million individuals falling into relative poverty in 2021.

139 Finally, if countries had matched their MDG shared prosperity premium during the SDGs (2005-2021),

140 the need for government assistance during the pandemic would have been substantially mitigated: in

1412020 , the continuation of MDG level of inclusive growth would have prevented almost 33 million cases

142 of relative poverty and 14 million cases of extreme poverty-approximately $60 \%$ of the cases of extreme

143 poverty prevented by governments' economic mitigation measures (Fig 4).

144

Discussion

145 Over the last four decades, the number of individuals living in extreme poverty declined by over 1.3

146 billion and the number of children under the age of 15 living in extreme poverty declined by 625 million.

147 Still, in 2019 , there were over 630 million living on less than $\$ 1.90$ a day-approximately $40 \%$ of whom

148 were children under the age of 15 . The past four decades also led to more equitable growth in the

149 standard of living, globally and within countries. The progress made to reduce extreme poverty

150 correlates with progress made on broader measures of development ${ }^{22,23}$ like reduction in child

151 mortality ${ }^{24,25}$, increased educational attainment ${ }^{26}$, political inclusion ${ }^{27}$, and expanded freedoms and

152 agency ${ }^{27}$. The progress made on achieving a more equitable world and equitable societies is slightly

153 counter to the conclusion of other analyses ${ }^{20,28}$ - potentially due to our focus on measuring the standard

154 of living, as opposed to income.

155 Starting in 2000, the MDGs set out to advance the standard of living of the poorest and most

156 vulnerable through unprecedented global cooperation and investment to expand access to education

157 and healthcare, reduce poverty, and alleviate inequality. During this time, we found almost three

158 quarters of countries grew inclusively and extreme poverty reduced three times faster than either the

159 preceding 20 years or the first four years of the SDGs. The failure to extend the level of MDG era

160 inclusive growth into the first four years of the SDGs left millions more individuals vulnerable to the 
161 economic damage caused by the COVID-19 pandemic. In response to the pandemic, many governments

162 around the world quickly provided $\$ 12$ trillion in economic relief, ${ }^{21}$ and these funds helped to mitigate

163 approximately $50 \%$ of the total cases of extreme poverty and $90 \%$ of the cases of relative poverty that

164 can be attributed to the pandemic in 2020.

165 Governments have quickly responded economically to the pandemic but the responses has been

166 uneven. While the average decline in GDP per capita in low- and middle income countries (LMICs) were

167 similar to GDP per capita declines in high-income countries in 2020 (approximately $7 \%$ decline) ${ }^{2}$, the

168 average government response to the economic fallout in high-income countries was nearly three times

169 larger than the response in LMICs - measured as government spending as a percentage of GDP (14\% vs

$1705 \%$ of GDP $)^{21}$. Hitherto, high-income countries have taken advantage of generous financial conditions to

171 fund government responses and prevent catastrophic economic scaring ${ }^{21}$. In contrast, LMICs are

172 financially constrained due to lack of access to financial markets, high borrowing costs, and worrisome

173 levels of debt, ${ }^{3,21}$ with over half of low-income countries in debt distress or at high-risk of distress ${ }^{21}$.

174 These financial constraints limit LMICs from mounting a proportional health response and preventing

175 cracks in economic foundations necessary for jumpstarting a recovery ${ }^{3}$. A lackluster response and

176 recovery only increases the odds of setting off a debt crisis, further imperiling the poor and jeopardizing

177 the global containment of an ever mutating, contagious virus ${ }^{29}$ in an interconnected world.

178 To date, the financial assistance provided to countries lacks in size, scope, and maybe

179 creativity. ${ }^{30-32}$ Many LMICs will need more assistance in the form of grants, loans, and debt servicing

180 relief to address their acute and unique challenges ${ }^{33}$ and prevent impending economic calamity. ${ }^{30}$

181 Fortunately, a growing chorus of leaders with power are planning "to go big" ${ }^{34}$ and substantially

182 enhance fiscal support for the most financially vulnerable countries. Post-pandemic, this mindset will

183 likely need to be carried over to avoid a long plodding recovery. A sustained and vigorous financial

184 commitment will help LMICs make investments ${ }^{3,21}$ that recover the quarter of a billion jobs lost in the 
185 pandemic - which largely supported the working poor ${ }^{35}$-and reclaim the pandemic-induced learning

186 losses that are projected to cost future generations upwards of USD 10 trillion. ${ }^{36}$ At this precarious

187 moment, making significant investments now can help LMICs take advantage of their favorable

188 demographics and spur a new era of inclusive growth ${ }^{3,21,37,38}$ rivaling the MDGs and deliver on the goal to

189 eradicate extreme poverty, alleviate inequality, and achieve sustainable development ${ }^{7-10}$ that gives rise

190 to more cohesive and resilient societies prepared to weather future shocks - whether they be in the

191 form of economic crisis, conflict, political instability, another pandemic, or a warming world.

192 
195 We used household surveys detailing either the value of income received by households or consumed 196 goods and services (exclusive of publicly provided education and healthcare services). Note, in this 197 analysis we use the term consumption and standard of living interchangeably. Consumption and income 198 measures are two distinct concepts. Cross-country analyses of poverty often note this distinction but 199 make no adjustment and pool these data together ${ }^{13}$. In contrast, we standardised all data to be 200 reflective of consumption by developing an income-to-consumption adjustment process using a boosted 201 regression tree (see supplementary information). Consumption was our preferred measure as it directly 202 reflects material wellbeing; measures of income are poorly predictive of material wellbeing in informal 203 or subsistence-based economies. Further details of the adjustment process may be found in the 204 methods annex.

The underlying data that fed our analysis was from the World Bank PovCaINet ${ }^{39}$, the United 206 Nations-World Institute for Development Economics (UN-WIDER) ${ }^{40}$, Luxembourg Income Study (LIS) ${ }^{41}$, 207 and Gallup World Poll surveys ${ }^{42}$. For select data sources we did not have access to underlying microdata, 208 only tabulation. We interpolated and standardized reported tabulations, see methods annex for details.

209 Tabulated data were often only presented at the national level which limited our ability to use these 210 data to estimate poverty and inequality at more granular levels (e.g. by age and urban/rural). This

211 limitation required us to develop a modeling procedure that made estimates at various levels of

212 granularity that were then scaled to the national level. In total, our data covered 179 country-years and 213150 countries within the past five years.

\section{Modeling}

215 Since not all data were available at the most granular level of analysis (e.g. urban/rural-age group level), 216 we made estimates at four levels that were reflective of the data availability. These modeling levels 
217 were the (i) national level, (ii) the urban and rural, (iii) urban and rural aggregated age group levels, and

218 (iv) urban and rural granular age group levels. Aggregated age groups corresponded to 0-14, 15-19, 20-

$21924 \ldots 60-64$, and 65 years of age or older; granular age groups corresponded to $0-4,5-9,10-14,15-20, \ldots$

$22060-64,65-69,70-74,75-79$, and 80 years of age or older. Age groups and urban and rural designations

221 were determined by the underlining survey data.

222

For each of the four modeling levels, we grouped the data by age group-urban/rural level (or the

223 lowest level of granularity possible) and calculated two measures from each group: the mean

224 consumption and the consumption Lorenz curve, respectively denoted by $\mu$ and $L(p)$. The mean

225 consumption reflects the average value of all goods and services consumed. The consumption Lorenz

226 curve reflects the cumulative share of total consumption against the respective cumulative population

227 percentiles. Together, mean consumption, $\mu$, and the consumption Lorenz curve, $L(p)$, can be used to

228 calculate the cumulative distribution of consumption, $F(x)$, by the following mathematical relationship

$$
F^{-1}(x)=\mu * L(p)^{\prime}(1)
$$

$230 F(x)$ is a smooth monotonically increasing function that reflects the percentage of the population living

231 under specific thresholds denoted by $x$-or the poverty rate at $x$. Inversely, $F^{-1}(x)$ provides the level of 232 consumption at population percentile $x$.

We estimated the mean consumption and consumption Lorenz curve at all four modeling levels

234 in 204 countries from 1980 to 2021. In total, we estimated 14 models: the mean consumption and

235 consumption Lorenz curve each estimated at the national level (1), urban level (2), rural level (3), urban

236 aggregated age groups (4), rural aggregated age group (5), urban granular age groups (6), rural granular 237 age groups (7).

We developed a novel two-step modeling procedure and applied it to estimate both the Lorenz curve and mean consumption model. In the first step of the modeling framework, we used a within- 
between model to regress mean consumption-or in the case of the consumption Lorenz curve,

241 cumulative share of total consumption at a given percentile-against a set of predictive covariates that

242 include GDP per capita, log percentage of the population with 12 years of education, log prevalence of

243 wasting, log natural resource exports as a percentage of GDP, log fraction of government expenditure

244 over GDP, log fraction of consumption over GDP, and a measure of universal health coverage. These

245 covariates were included on the basis of theoretical relationship, historical precedence, and statistical

246 significance and were sourced from the Global Burden of Disease (GBD) study ${ }^{24,43,44}$. In the case of the

247 Lorenz curve, covariate effects were allowed to vary across population percentiles. Further details on

248 covariate selection and estimation process may be found in the supplementary information The within-

249 between model was useful in our application as the model was capable of explaining within country

250 variation - accounting for unobserved time-invariant country factors - and between country variation-

251 useful in making predictions in countries where we had no survey data.

The within-between model may not have accounted for all measureable heterogeneity across

253 time and within country or region. To help account for this heterogeneity, we smoothed the residuals

254 from the within-between model over time in a series of cascading Gaussian Process Regressions

$255(\mathrm{GPRs})^{45}$. In the case of the Lorenz curve, we smoothed over population percentiles in addition to time;

256 in the case of models by age group, we additionally smoothed over age to benefit from the correlated

257 age patterns. The GPR cascade flowed down a modeling cascade defined by the GBD geographical

258 hierarchy. This modeling framework is similar to other modeling frameworks used to estimate globally

259 relevant health and financial statistics ${ }^{43,44}$. A more complete description of the modeling framework is

260 available in the supplementary information.

After estimation, we used our estimates of mean consumption, consumption Lorenz curve, and

262 equation 1, to calculate seven cumulative consumption distributions (national, urban, rural, urban-age

263 aggregated, rural-age aggregated, urban-age group, rural age-group). However, due to the independent 
nature of the modeling, these cumulative consumption distributions may not be internally consistent

265 across all modeling levels. We ensured internal consistency through a process of sequential scaling of all

266 estimates to the national level estimates, as the national level estimates were supported by more data.

267 Uncertainty was propagated fully throughout the modeling process. The supplementary information

268 provides more details on these processes.

\section{Forecasting}

270 We forecasted the cumulative distribution of consumption in a panel regression model to predict

271 poverty rates in 2020 and 2021. By modeling the cumulative distribution of consumption as the

272 dependent variable, we account for both the magnitude of changes in consumption as well as the

273 distribution of consumption. The panel model regressed estimates of the cumulative distribution of

274 consumption at 99 percentiles $\left(1^{\text {st }}-99^{\text {th }}\right)$ against the population percentiles, GDP per capita, and general

275 government expenditure as a fraction of GDP (GGE) and the interaction between population percentiles

276 and GDP per capita and GGE. Since our dependent variable was estimated, we inversed variance

277 weighted the data to give more weight to estimates with greater certainty.

We developed a total of four forecast scenarios: (1) a scenario without COVID-19, (2) a scenario

279 with COVID-19 without government intervention, (3) a scenario with COVID-19 but with government

280 intervention, (4) and a scenario with COVID-19 that includes no government response but countries at

281 least matched their MDG shared prosperity premium from 2016 to 2021.

For scenario 1, we used previously published forecast of GDP and GGE that neglect all impacts

283 from COVID-1946. For scenario 2, we used forecast of GDP out to the year 2021 that account for the

284 economic effects of the COVID-19 pandemic ${ }^{2}$; for GGE forecast to the year 2021, we used model

285 predictions form a regressing GGE against GDP forecast sensitive to COVID-19. For scenario 3, we used 
scenario 2's forecast of GDP and GGE but we added to the GGE forecast "above the line" government

287 spending that was provided in response to the COVID-19 pandemic ${ }^{21}$.

For scenario 4, we used predictions from scenario 2, however, we forced each country's cumulative distributions of consumption to at least match their MDG shared prosperity premium. We achieved this by first calculating each country's shared prosperity premium during the MDGs by differencing countries' annualized change in mean consumption of the poorest $40 \%$ and the annualized 292 change in overall mean standard of living. Secondly, from 2015 to 2021, we calculated countries' shared 293 prosperity premium for each year. If, for a given country-year between 2015 and 2021, the calculated 294 shared prosperity premium was less than the country's shared prosperity premium during the MDGs, we 295 inflated consumption levels of the bottom $40 \%$ to match the country's MDG shared prosperity premium 296 level.

\section{Reported statistics}

298 All reported poverty counts were made using published population estimates ${ }^{47}$ and UN Urbanization

299 Project ${ }^{17}$ estimates of the proportion of the population living in urban and rural areas by age ${ }^{16,17}$.

300 Estimates of the relative poverty rate were made using country-specific poverty thresholds defined as $30150 \%$ of the median consumption of the population. Relative poverty estimates for 2020 and 2021 were 302 calculated using 2019 country-specific poverty thresholds, per recommendations for reporting relative 303 poverty rates during times of extreme economic volatility ${ }^{48}$.

Our estimates of the number of cases of poverty prevented by inclusive growth (or cases of poverty due to the failure to grow inclusively) were estimated similarly to the process described in 306 forecast scenario 4. We first calculated the shared prosperity premium from 1980 to 2000 and the 307 shared prosperity premium during the MDGs. To calculate the number of cases of poverty that could 308 have been prevented by growing inclusively, we took all countries with a negative shared prosperity 309 premium and inflated the consumption of the bottom $40 \%$ so the shared prosperity premium equaled 
zero. We then compared poverty rates from the new cumulative distributions of consumption and to

311 the previous poverty rates. To calculate the number of cases of poverty that were due to inclusive

312 growth, we took all countries with a positive shared prosperity premium, deflated consumption levels of

313 the bottom $40 \%$ until the shared prosperity premium equaled zero, and recalculated poverty rates from

314 the new cumulative distribution of consumption.

315 Limitations

316 As with any modeling exercise, our analysis comes with limitations. For example, no uniform

317 questionnaire exists to elicit household consumption or income. Inevitably, the lack of uniformity in

318 questionnaires increases the variation of measures reported from surveys and potentially disrupted

319 cross-country comparisons, and within-country trends. In many countries there is often infrequent data

320 collection leading to large gaps in data. We minimized this limitation as much as possible by leveraging

321 the largest collection of poverty and inequality related data. In India, as an example, similar "now

322 casting" exercises of poverty rely on an Indian survey that was taken in 2011 to predict present poverty;

323 in contrast, we leveraged six Indian surveys between 2011 and the present to predict and forecast levels

324 of poverty in India.

Further, our definition of urban and rural followed administrative definitions, opposed to

326 population density cutoffs. This decision was made because surveys we draw upon most often classify

327 respondents as urban and rural based of the country's administrative definition. In the estimation

328 process, these heterogeneous definitions or urban and rural are hopefully accounted for by the country

329 level effects used in our regressions. While the estimates of urban and rural poverty may not be

330 perfectly comparable across countries, these administrative definitions may be of more relevance to

331 country-level officials compared to globally defined and imposed definitions of urban and rural.

332 Admittedly, a more significant issue in comparing urban and rural estimates of poverty is the variation in 
333 price levels. While our data uses World Bank developed urban and rural PPPs for populous countries like

334 India, China, and Indonesia, urban and rural PPPs are not widely available for many countries.

Importantly, our measurement of poverty reflected individuals living in households spending

336 less than $\$ 1.90$ a day. This definition ignores intra-household allocations. Although this is common

337 practice in poverty research, this simply means our measure of poverty is more reflective of the actual

338 household unit than the actual individual. Additionally, we could further improve upon our income-to

339 consumption adjustment process by accounting for attributes of survey instruments used to elicit levels

340 of consumption -instead of our current approach of treating all instruments uniformly. Finally, our

341 forecast of poverty to the year 2021 are heavily reliant on forecasted GDP per capita and the tracking of

342 government responses to the pandemic. Given the unique nature of the pandemic, our forecast model

343 based on historical data likely does not capture all of the effects of the pandemic on poverty. In the

344 future, integrating high-frequency data into the estimation process could facilitate real-time poverty

345 estimation.

346 Data and Code availability

347 The underlying data in this study were sourced from four sources: the World Bank

348 (http://iresearch.worldbank.org/PovcalNet/povOnDemand.aspx), the UNU-WIDER inequality database

349 (https://www.wider.unu.edu/project/wiid-\%E2\%80\%93-world-income-inequality-database), the LIS

350 database (https://www.lisdatacenter.org), and Gallup World Poll

351 (https://www.gallup.com/178667/gallup-world-poll-work.aspx). The code base used in this analysis may

352 be accessed with the following link https://cloud.inme.washington.edu/s/8JZfgKMANKXTM7D.

$353 \quad$ Figure titles and notes 
Panel A displays global extreme poverty counts-number individuals in households spending less than a \$1.90 a day per person-- by country/region and urban/rural from 1980 to 2019. The darkly shaded areas represent urban areas and the lightly shaded regions represent rural area. Panel B display global extreme poverty rates-or the percentage of the world's population living in households spending less than $\$ 1.90$ a day per person-over time by urban and rural areas. The dashed lines in Panel B represent $95 \%$ uncertainty intervals. Panel $C$ and $D$ respectively display absolute extreme and relative poverty rate estimates in 2019. Countries that have eradicated extreme poverty-extreme poverty rate of 360 less than $3 \%$-are colored in grey.
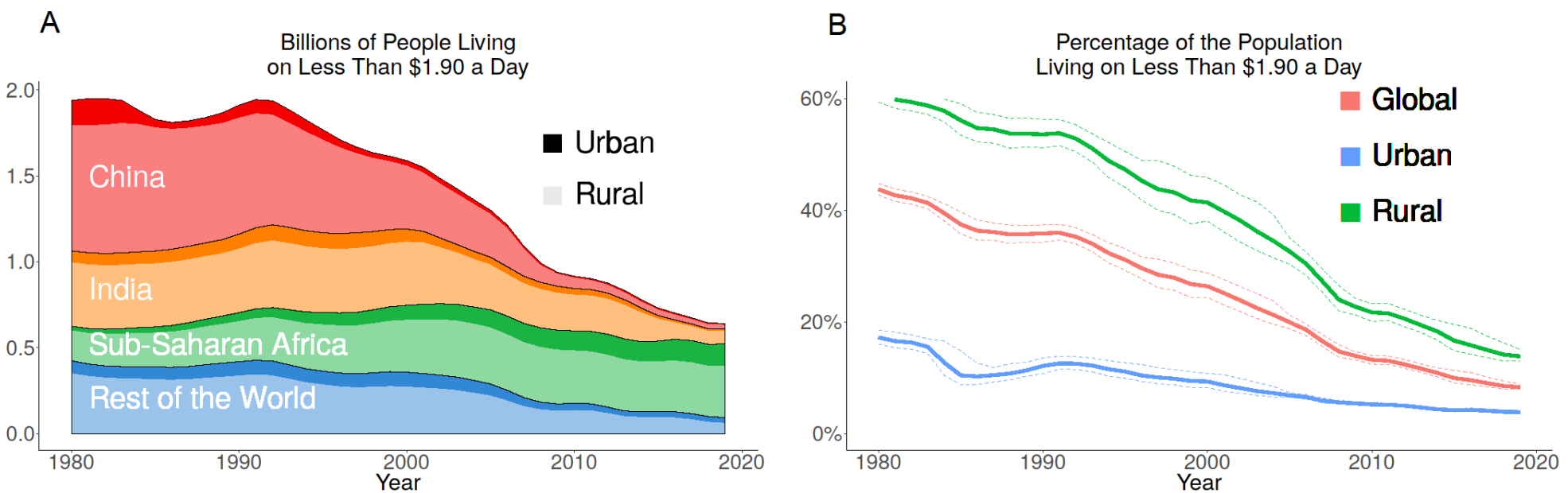

B

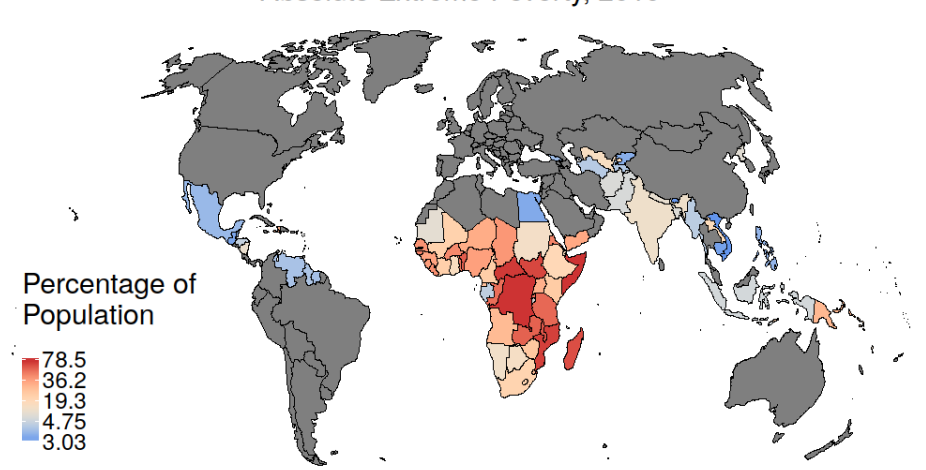

C

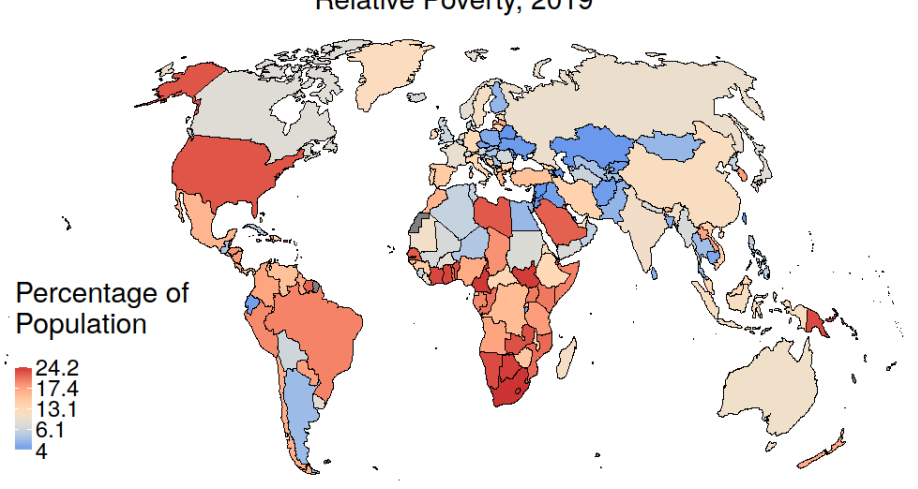


Figure \#2: Population pyramid by poverty threshold in 1980 and 2019 by rural and urban globally.

363 Figures display the number of individuals living under each threshold. Thresholds values of \$1.90, \$3.20, $364 \$ 5.50$, and $\$ 21.70$ a day are established by the World Bank. The threshold of $\$ 11$ dollars is the lower 365 bound of the global middle class.

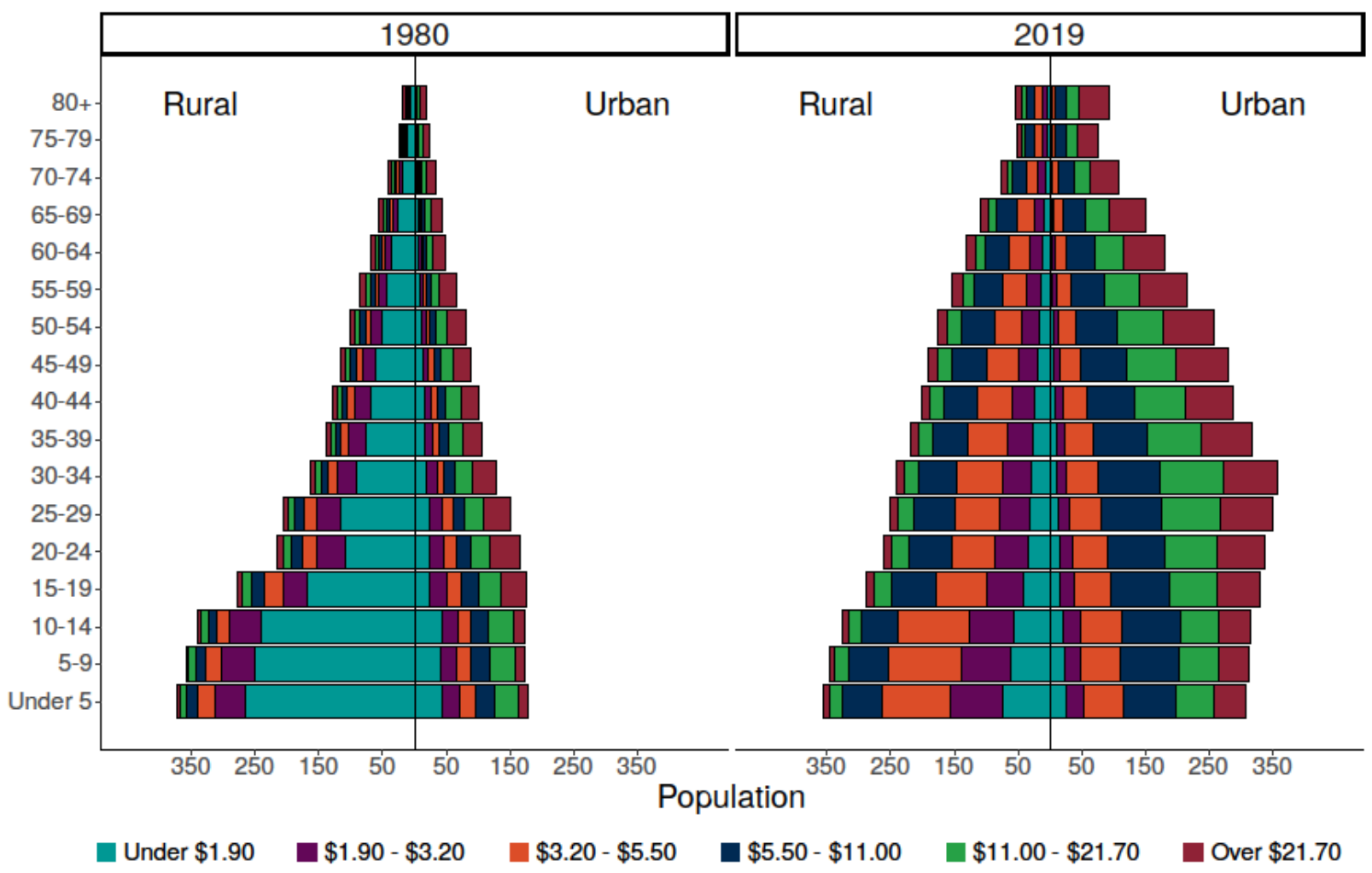


Figure \#3: Annualized growth across standard of living percentile both globally and the average across countries.

Panel A displays the annualized growth in the standard of living across global standard of living percentiles in four time periods. Figure was created by simulating the world's population at $1000^{\text {th }}$ the scale. A population proportional number of simulants was generated from each country's cumulative distribution of consumption; for a given year, all countries simulants were pooled together, ranked from poorest to wealthiest, and percentile standard of living levels were then calculated. The annualized change within a percentile is the line displayed in Panel A. Panel B was generated similarly to Panel A, excepts simulants were not pooled across countries. Instead, annualized changes across time in the standard of living for each percentile were calculated within a specific country, and then we averaged the annualized change across countries for each percentile.

\section{Global}

Change in Standard of Living

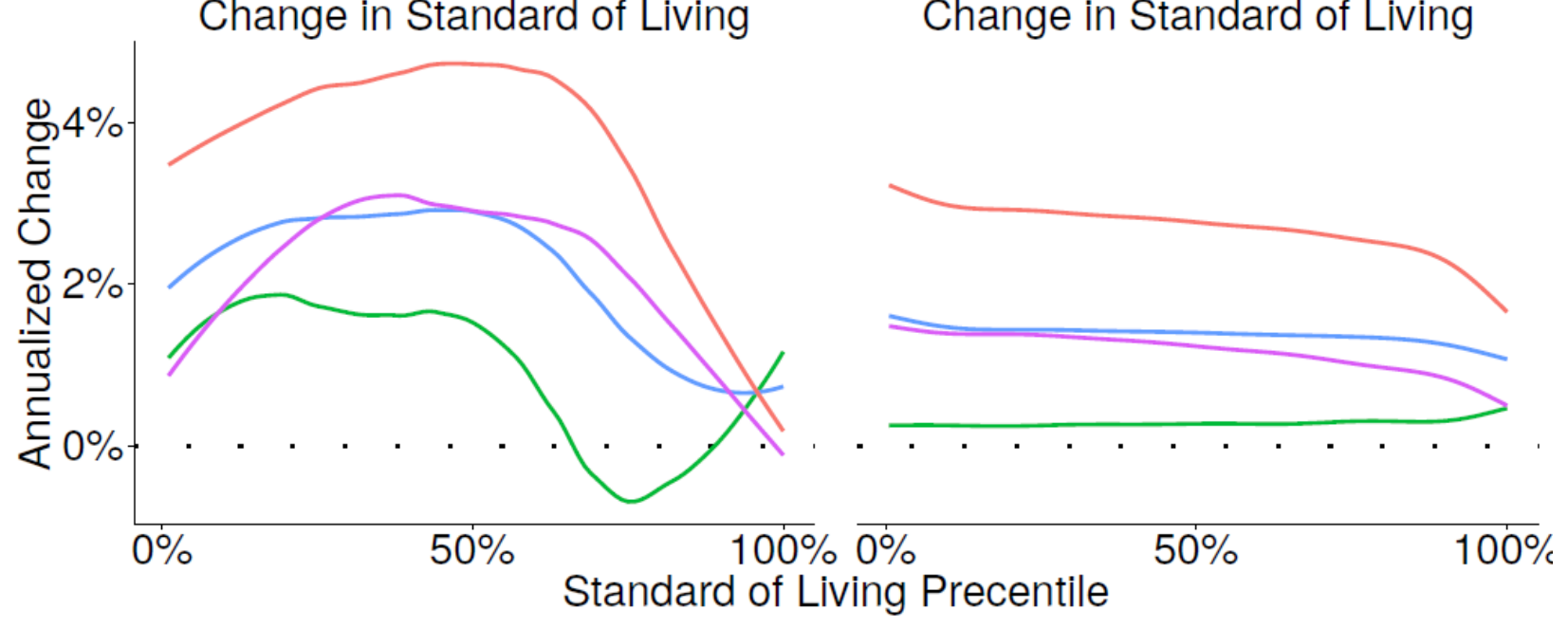


381

382

383

384

385

\section{Figure \#4: Extreme and relative poverty forecast scenarios.}

Analysis is limited to 175 countries where the International Monetary Fund tracks "above the line" government spending in response to the pandemic. These 175 countries encompass 99\% of the world's population and 97\% of the world's extremely impoverished in 2019. Government spending in response to the pandemic in these 175 countries was forecasted out to the year 2021
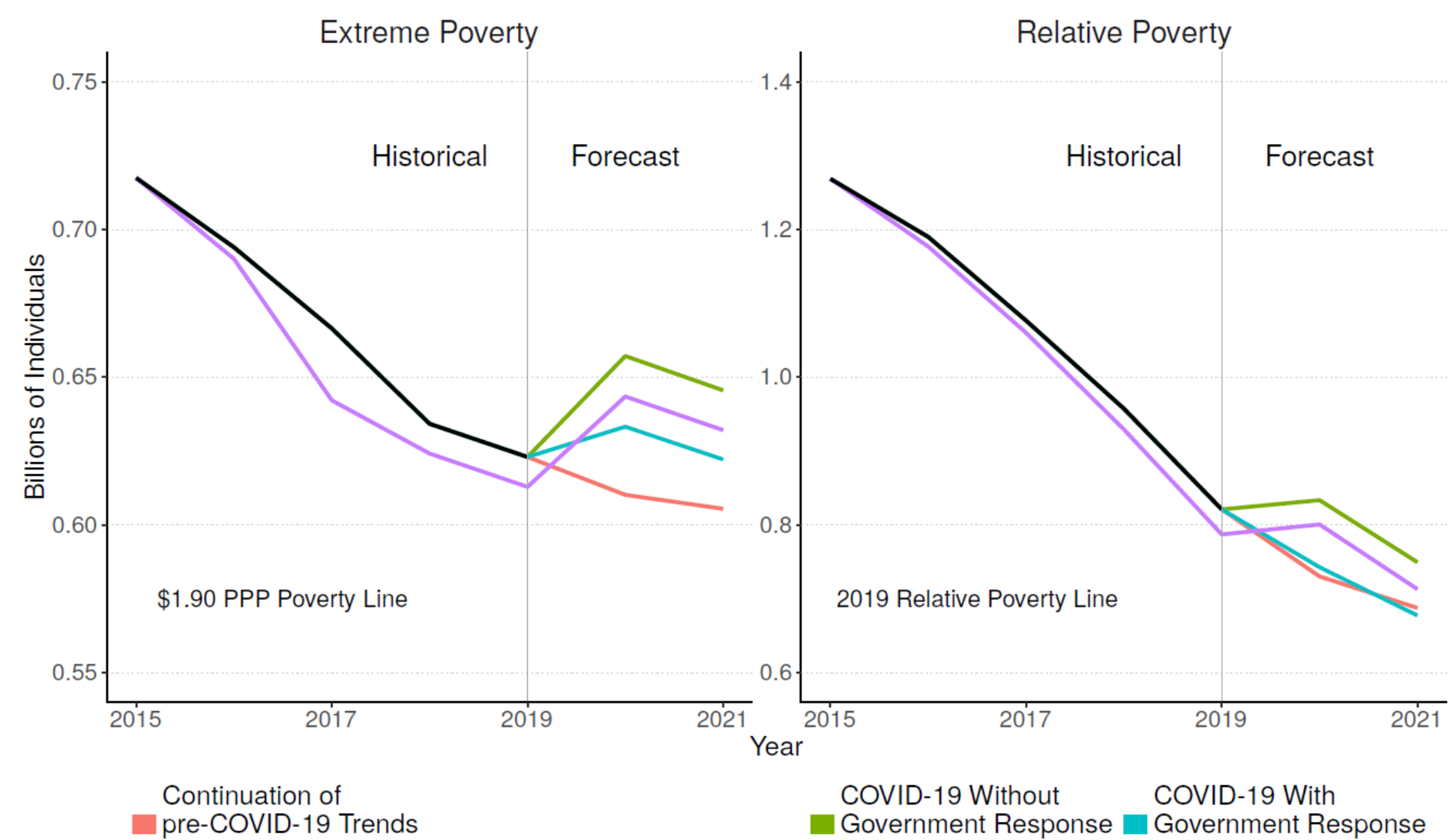

Continuation of
pre-COVID-19 Trends

Government Response Government Response

Continuation of MDG era Shared Prosperity Premium; COVID-19 Without Government Response

Historical Estimates 


\section{Extended Data Figure \#1: Population pyramid by poverty threshold in 1980 and 2019 by rural and urban globally across regions and country.}

Figures display the number of individuals living under each threshold. Thresholds values of $\$ 1.90, \$ 3.20, \$ 5.50$, and $\$ 21.70$ a day are established by the World Bank. The threshold of $\$ 11$ dollars is the lower bound of the global middle class.
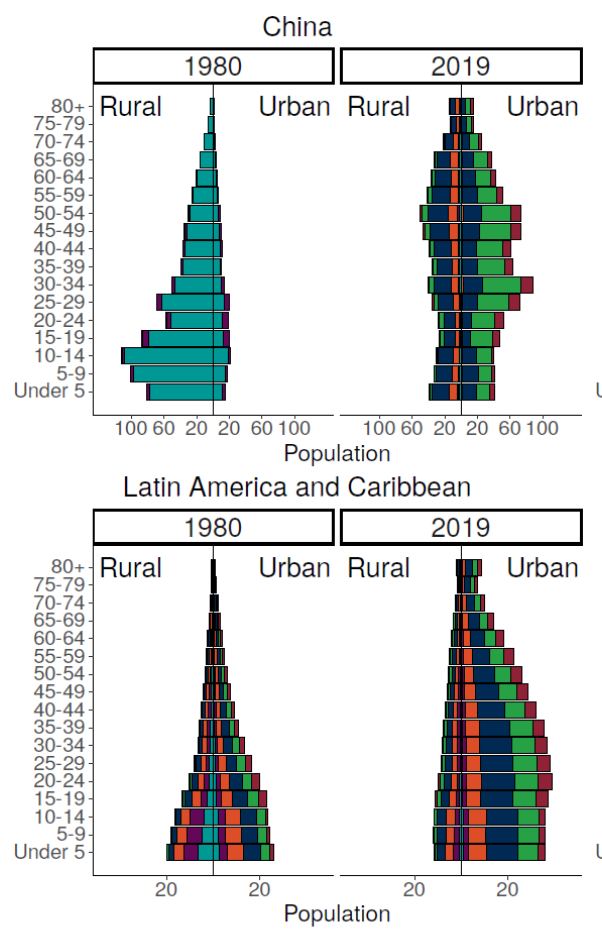
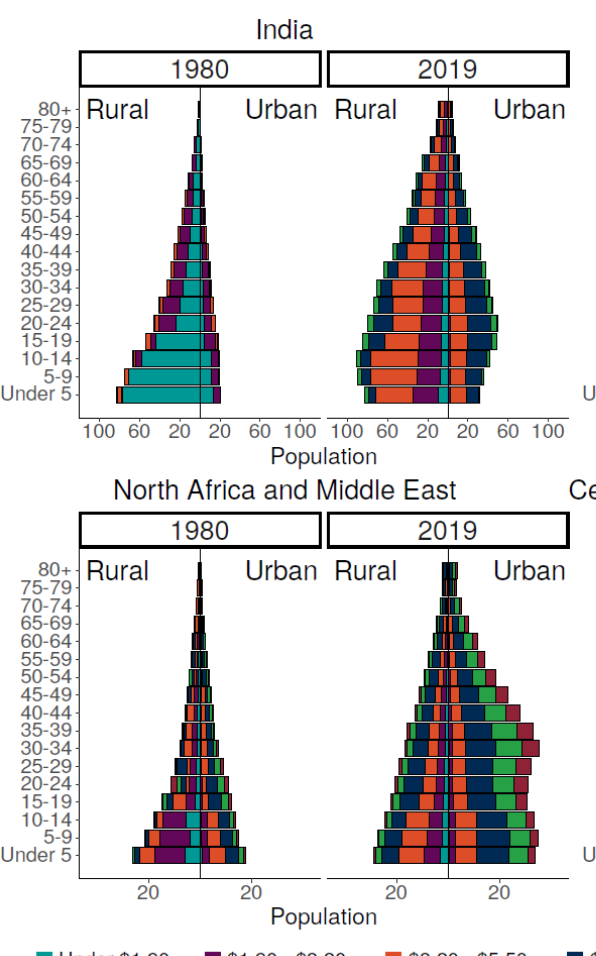

Under $\$ 1.90 \quad \$ 1.90-\$ 3.20 \quad \$ 3.20-\$ 5.50$

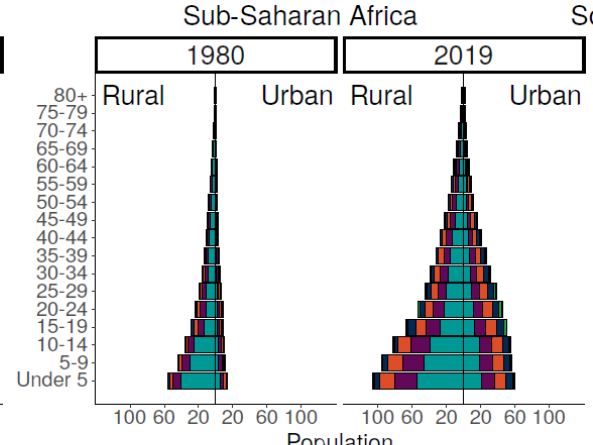

Central Europe, Eastern Europe, and Central Asia

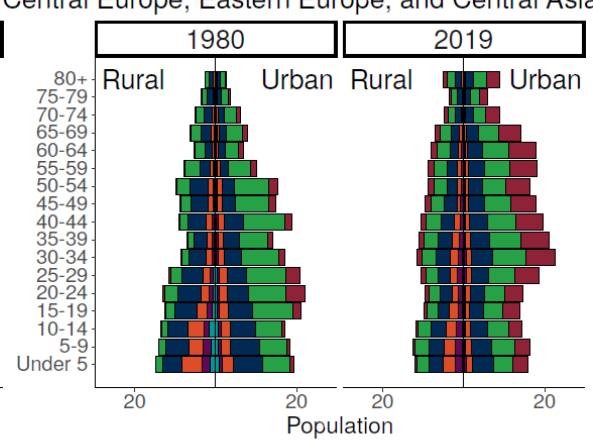

Ш $\$ 5.50-\$ 11.00 \quad \$ 11.00-\$ 21.70 \quad$ Over $\$ 21.70$
South Asia, Southeast Asia, East Asia, and Ocean
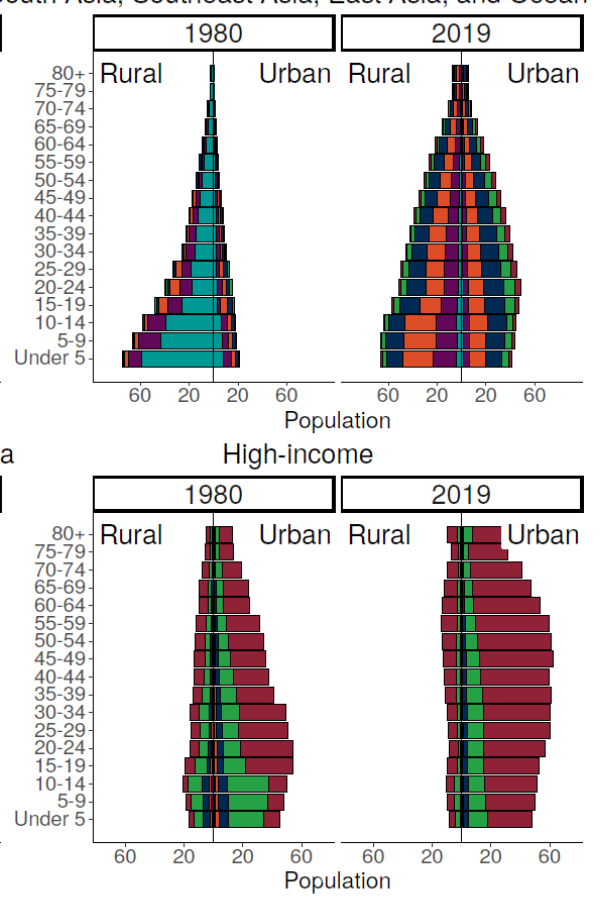
393 Panel B displays the composition-or percentage - of individuals from each regions or each country within a global standard of living percentile 394 for each time period. The bottom $x$-axis in panel $B$ reflects the global standard of living percentile; the top $x$-axis in panel $B$ reflects the position of
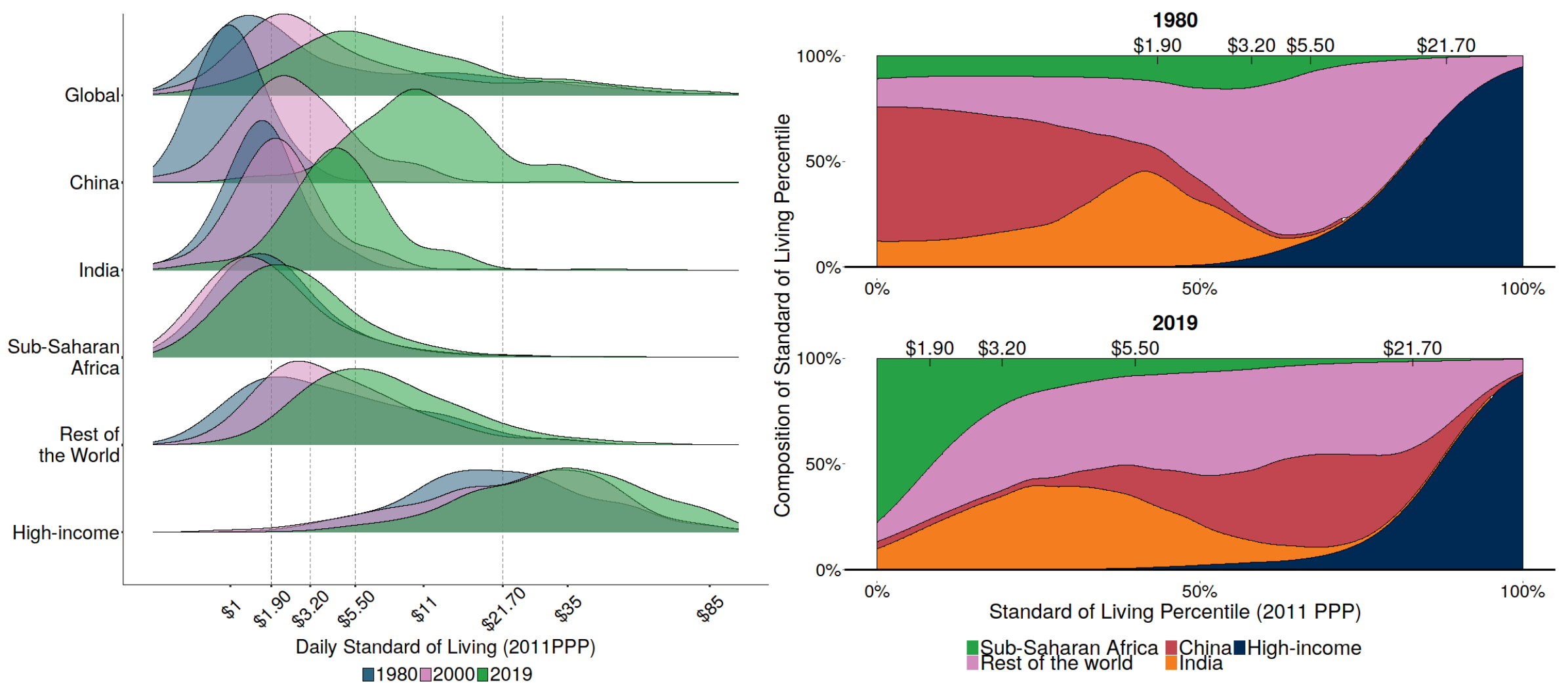
397

\section{Extended Data Figure \#3: Annualized percentage change and absolute global growth across standard of living percentile by region and}

country.

Panel A displays the annualized growth in the standard of living across global standard of living percentiles in four time periods. Figure was created by simulating the world's population at $1000^{\text {th }}$ the scale. A population proportional number of simulants was generated from each country's cumulative distribution of consumption; for a given year, all countries simulants were pooled together, ranked from poorest to wealthiest, and percentile standard of living levels were then calculated. The annualized change within a percentile is the line displayed in Panel A. Absolute growth was determined similarly to annualized percentage change, except the annual absolute growth was calculated.
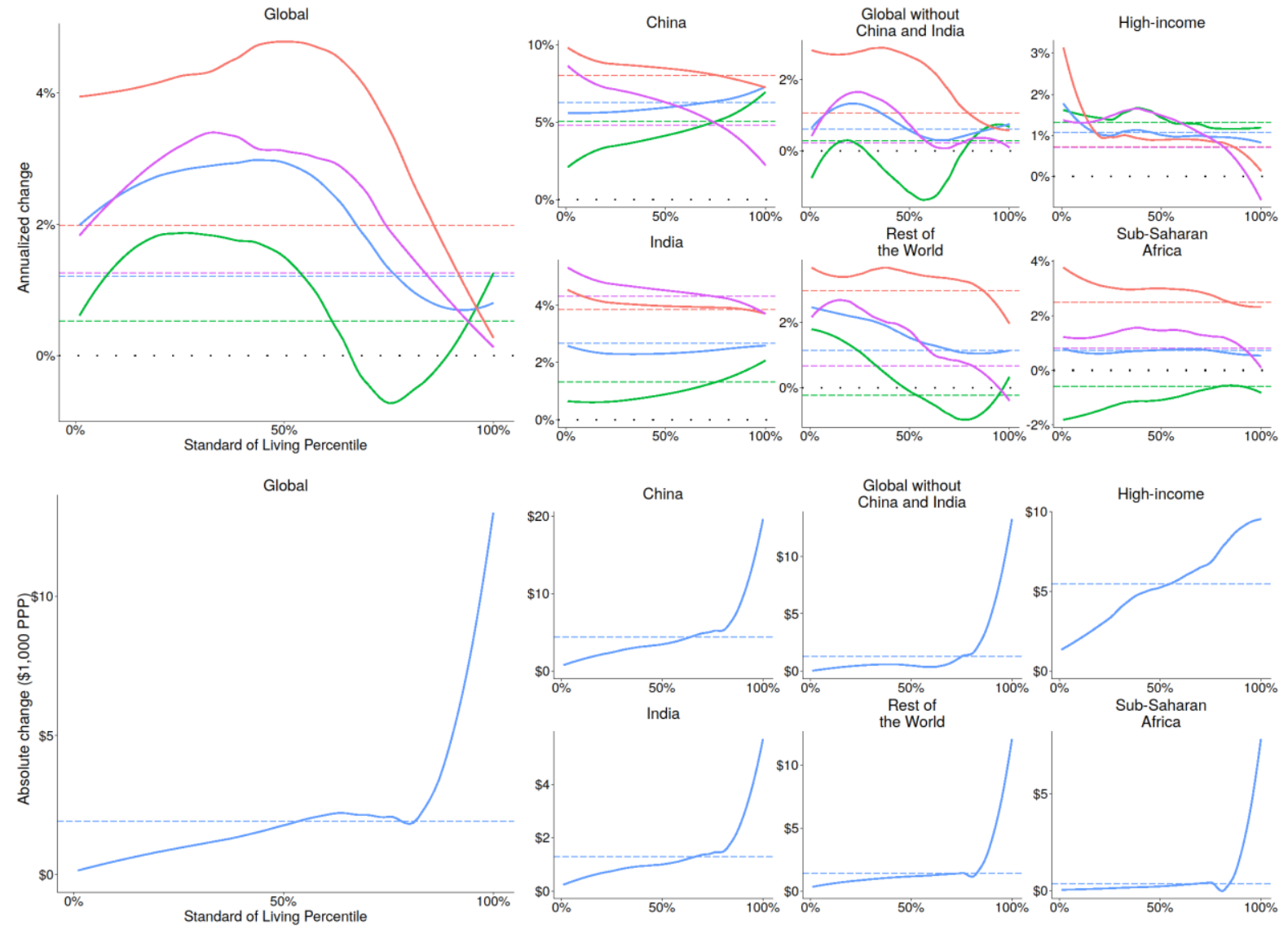

High-income

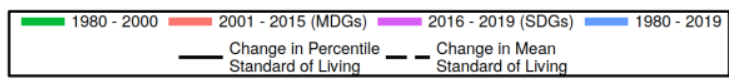


Extended Data Figure \#4: Percentage of countries growing inclusively across three time periods.

406 Shared prosperity premium was calculated by subtracting the growth rate of the mean standard of living 407 from the growth rate of the mean standard of living of the bottom $40 \%$.

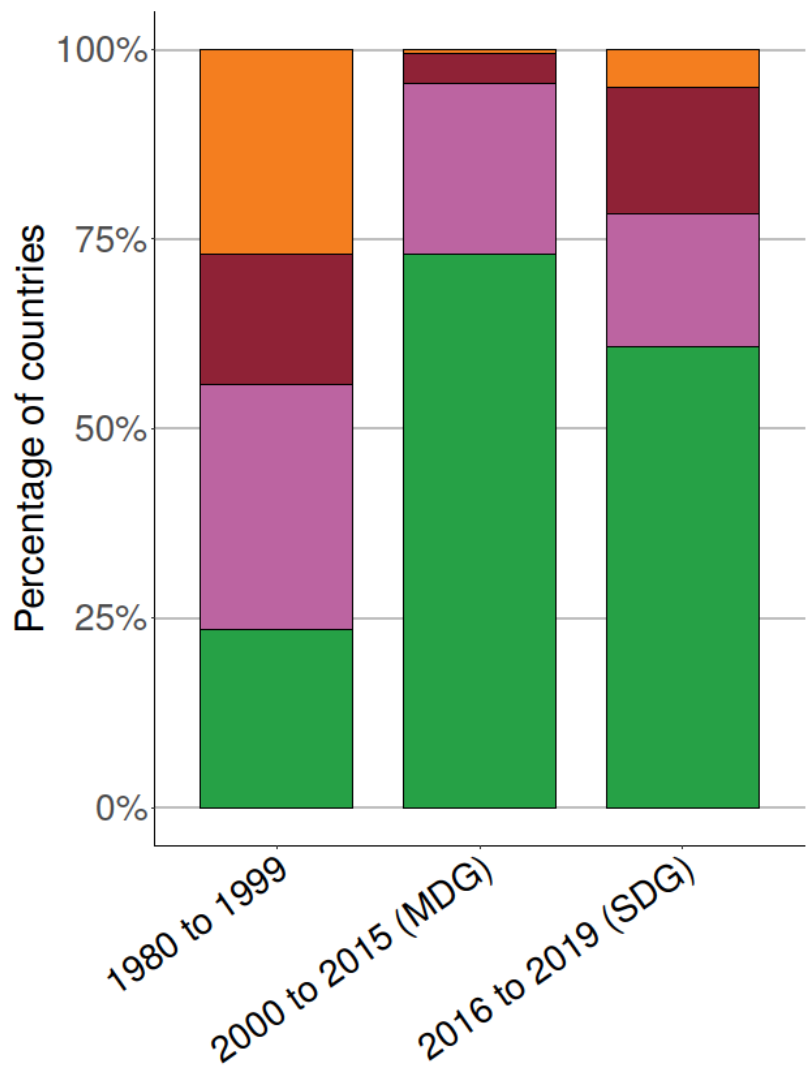

Inclusive Growth: Growth in mean standard of living with positive shared prosperity premium

Growth in mean standard of living with negative shared prosperity premium

Declining mean standard of living with negative shared prosperity premium

Declinig mean standard of living with positive share prosperity premium 
411 1. World Bank. Poverty and Shared Prosperity 2020: Reversals of Fortune. (2020).

412 2. International Monetary Fund. World Economic Outlook, October 2020: A Long and Difficult Ascent.

413 3. World Bank. Global Economic Prospects. (2021).

414 4. Osborn, D., Cutter, A. \& Ullah, F. Universal Sustainable Development Goals.

415 5. The United Nations General Assembly. Transforming our world: the 2030 Agenda for Sustainable 416 Development. (2015).

417 6. Nilsson, M., Griggs, D. \& Visbeck, M. Policy: Map the interactions between Sustainable Development $418 \quad$ Goals. Nat. News 534, 320 (2016).

419 7. Weitz, N., Carlsen, H., Nilsson, M. \& Skånberg, K. Towards systemic and contextual priority setting 420 for implementing the 2030 Agenda. Sustain. Sci. 13, 531-548 (2018).

421 8. Pradhan, P., Costa, L., Rybski, D., Lucht, W. \& Kropp, J. P. A Systematic Study of Sustainable 422 Development Goal (SDG) Interactions. Earths Future 5, 1169-1179 (2017).

423 9. Fuso Nerini, F. et al. Connecting climate action with other Sustainable Development Goals. Nat. $424 \quad$ Sustain. 2, 674-680 (2019).

425 10. Lusseau, D. \& Mancini, F. Income-based variation in Sustainable Development Goal interaction 426 networks. Nat. Sustain. 2, 242-247 (2019).

427 11. United Nations. The Millennium Development Goals Report 2015. (2015).

428 12. Deaton, A. The Analysis of Household Surveys: A Microeconometric Approach to Development Policy. 429 (World Bank Group, 2018).

430 13. Lahoti, R., Jayadev, A. \& Reddy, S. G. The Global Consumption and Income Project (GCIP): An $431 \quad$ Introduction and Preliminary Findings. 26.

432 14. United Nations. SDG Indicators. https://unstats.un.org/sdgs/metadata/.

433 15. World Bank. Poverty and Shared Prosperity 2018: Piecing Together the Poverty Puzzle. (2018). 
434 16. Vollset, S. E. et al. Fertility, mortality, migration, and population scenarios for 195 countries and 435 territories from 2017 to 2100: a forecasting analysis for the Global Burden of Disease Study. The Lancet S0140673620306772 (2020) doi:10.1016/S0140-6736(20)30677-2.

17. United Nations, Department of Economic and Social Affairs, \& Population Division. World urbanization prospects: the 2018 revision. (2019).

439 18. Bui, Q. The Geography of U.S. Inequality. The New York Times (2016).

440 19. Shooting an elephant. The Economist (2016).

441 20. Milanovic, B. \& Lakner, C. Global Income Distribution: From the Fall of the Berlin Wall to the Great 442 Recession | The World Bank Economic Review | Oxford Academic. World Bank Econ. Rev. (2012).

443 21. International Monetary Fund. Fiscal Monitor: Policies for the Recovery. (2020).

444 22. Sen, A. Development As Freedom. (New York: Anchor Books, 2000).

445 23. Ross, B., Brinley, J., Caponio, J., Trott, C. \& Wilson, E. Charting pathways out of multidimensional 446 poverty: Achieving the SDGs.

447 24. Wang, H. et al. Global age-sex-specific fertility, mortality, healthy life expectancy (HALE), and 448 population estimates in 204 countries and territories, 1950-2019: a comprehensive demographic 449 analysis for the Global Burden of Disease Study 2019. The Lancet 396, 1160-1203 (2020).

450 25. Burstein, R. et al. Mapping 123 million neonatal, infant and child deaths between 2000 and 2017. $451 \quad$ Nature 574, 353-358 (2019).

452 26. Friedman, J. et al. Measuring and forecasting progress towards the education-related SDG targets. $453 \quad$ Nature 580, 636-639 (2020).

454 27. Lührmann, : Anna et al. Democracy Report 2020: Autocratization Surges-Resistance Grows. (2020). 455 28. Alvaredo, F., Chancel, L., Piketty, T., Saez, E. \& Zucman, G. The Elephant Curve of Global Inequality 456 and Growth. AEA Pap. Proc. 108, 103-108 (2018). 
29. Tegally, H. et al. Emergence and rapid spread of a new severe acute respiratory syndrome-related coronavirus 2 (SARS-CoV-2) lineage with multiple spike mutations in South Africa. medRxiv 2020.12.21.20248640 (2020) doi:10.1101/2020.12.21.20248640.

30. European Network on Debt and Development. The G20 Debt Service Suspension Initiative. (2020).

31. Cohen, C. et al. The Role of State-Contingent Debt Instruments in Sovereign Debt Restructurings.

32. Communiqué: G20 Finance Ministers and Central Bank Governors, April 15, 2020. http://www.g20.utoronto.ca/2020/2020-g20-finance-0415.html.

33. Kharas, H. \& Dooley, M. COVID-19's legacy of debt and debt service in developing countries. 32.

34. Lawder, D. Yellen urges G7 to 'go big' on stimulus, says U.S. committed to multilateralism. Reuters (2021).

35. International Labour Organization. COVID-19 and the world of work: Sixth edition. (2020).

36. Azevedo, J. P., Hasan, A., Goldemberg, D., Iqbal, S. A. \& Geven, K. Simulating the Potential Impacts of COVID-19 School Closures on Schooling and Learning Outcomes: A Set of Global Estimates. (World Bank, Washington, DC, 2020). doi:10.1596/1813-9450-9284.

37. World Bank. Africa Cities: Opening the World. (2017).

38. World Bank. Beyond the gap: how countries can afford the infastructure they need while protecting the planet. (2019).

39. World Bank. PovcalNet. http://iresearch.worldbank.org/PovcalNet/home.aspx.

40. UNU-WIDER : World Income Inequality Database (WIID). UNU-WIDER https://www.wider.unu.edu/project/world-income-inequality-database-wiid (2020).

41. LIS Cross-National Data Center in Luxembourg. https://www.lisdatacenter.org/.

42. Gallup. Gallup World Poll. 
479 43. James, S. L. et al. Global, regional, and national incidence, prevalence, and years lived with disability 480 for 354 diseases and injuries for 195 countries and territories, 1990-2017: a systematic analysis for 481 the Global Burden of Disease Study 2017. The Lancet 392, 1789-1858 (2018).

482 44. Chang, A. Y. et al. Past, present, and future of global health financing: a review of development 483 assistance, government, out-of-pocket, and other private spending on health for 195 countries, 484 1995-2050. The Lancet 393, 2233-2260 (2019).

485

45. GPflow: a Gaussian process library using tensorflow: The Journal of Machine Learning Research: Vol 486 18, No 1. https://dl.acm.org/doi/abs/10.5555/3122009.3122049.

487

46. Micah, A. E. et al. Health sector spending and spending on HIV/AIDS, tuberculosis, and malaria, and 488 development assistance for health: progress towards Sustainable Development Goal 3. The Lancet 396, 693-724 (2020).

490

47. Vollset, S. E. et al. Fertility, mortality, migration, and population scenarios for 195 countries and territories from 2017 to 2100: a forecasting analysis for the Global Burden of Disease Study. The Lancet 396, 1285-1306 (2020).

48. OECD. Society at a Glance 2019 OECD Social Indicators: OECD Social Indicators. (OECD Publishing, 494 2019).

495 